\title{
Hepatic Arterial Infusion with Tumor Necrosis Factor- $\alpha$ Induces Early Hepatic Hyperperfusion
}

\author{
T. Schäfer ${ }^{a} \quad J . S_{\text {Sperling }}^{a} \quad$ J.E. Slotta ${ }^{a} \quad$ O. Kollmar ${ }^{a} \quad$ M.K. Schilling ${ }^{a} \quad$ M.D. Menger ${ }^{b}$ \\ S. Richter ${ }^{a}$ \\ ${ }^{a}$ Department of General, Visceral, Vascular and Pediatric Surgery and ${ }^{\mathrm{b}}$ Institute for Clinical and Experimental \\ Surgery, University of Saarland, Homburg/Saar, Germany
}

\section{Key Words}

Hepatic arterial infusion $\cdot$ Tumor necrosis factor- $\alpha \cdot$

Hepatic hyperperfusion - Regional chemotherapy

\begin{abstract}
Background: Hepatic arterial infusion (HAl) has been developed for high-dose regional chemotherapy of unresectable liver metastases or primary liver malignancies. While it is well known that high concentrations of tumor necrosis factor (TNF)- $\alpha$ damage tumor blood perfusion, there is no information on whether autochthonous liver perfusion is affected by $\mathrm{HAl}$ with TNF- $\alpha$. Therefore, we investigated the effects of HAI with TNF- $\alpha$ on hepatic macro- and microvascular perfusion. Methods: Swabian Hall pigs were randomized into three groups. HAl was performed with either 20 or $40 \mu \mathrm{g} / \mathrm{kg}$ body weight TNF- $\alpha$ ( $n=6$ each group). Saline-treated animals served as controls $(n=6)$. Analyses during a 2-hour post-HAl observation period included systemic hemodynamics, portal venous and hepatic arterial blood flow, portal venous pressure, and the blood flow in the hepatic microcirculation. Results: HAI with TNF- $\alpha$ caused a slight decrease of mean arterial blood pressure $(p<0.001)$, which was compensated by a moderate increase of heart rate $(p<0.001)$. No further systemic side effects of TNF- $\alpha$ were observed. HAI with TNF$\alpha$ further caused a slight but not significant decrease of por-
\end{abstract}

tal venous blood flow $(p=0.737)$ in both experimental groups, paralleled by an increase of hepatic arterial blood flow $(p=0.023,20 \mu \mathrm{g} / \mathrm{kg} ; \mathrm{p}=0.034,40 \mu \mathrm{g} / \mathrm{kg})$ resulting in an overall hepatic hyperperfusion. The hepatic hyperperfusion after HAl with $20 \mu \mathrm{g} / \mathrm{kg}$ TNF- $\alpha$ was more pronounced and associated with a $40 \%$ decrease of the blood flow in the hepatic microcirculation $(p=0.009)$. HAl with $40 \mu \mathrm{g} / \mathrm{kg}$ TNF- $\alpha$ was only associated with a temporary and moderate total hepatic hyperperfusion and did not affect the blood flow in the hepatic microcirculation. Conclusion: HAI with TNF- $\alpha$ causes a decrease of portal venous flow; however, this is overcompensated by an increased hepatic arterial blood flow, resulting in a total hepatic hyperperfusion. Moderate total hepatic hyperperfusion does not affect the blood flow in the hepatic microcirculation, while a persistent and more pronounced hyperperfusion may cause hepatic microcirculatory disturbances.

Copyright $\odot 2012$ S. Karger AG, Basel

\section{Introduction}

It is well known that blood supply of liver metastases is mainly derived from the hepatic artery (HA), whereas the normal liver tissue is supplied by both the portal venous (PV) and the hepatic arterial system $[1,2]$. Based on

\section{KARGER}

Fax +4161306 1234 E-Mail karger@karger.ch www.karger.com

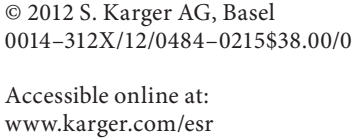

Thilo Schäfer, MD

Department of General, Visceral, Vascular and Pediatric Surgery

University of Saarland

DE-66421 Homburg/Saar (Germany)

Tel. +496841 163 0000,E-Mail thilo.schaefer@uks.eu 
this knowledge, hepatic arterial infusion (HAI) has been developed for regional chemotherapy of liver metastases [3]. Due to the first pass effect of the liver and the predominant arterial blood supply of tumors, HAI results in higher exposure of the tumor tissue to chemotherapeutic drugs and less systemic side effects than systemic application $[4,5]$. Although several clinical studies have reported increased response rates of metastases after HAI [6-10], a survival benefit has only been proven in few studies [7]. Thus, HAI has not yet become a standard therapy for the treatment of liver metastases [11].

However, recent studies with modern anticancer drugs eventually may redefine the potentials of HAI for eradication of liver metastases [12-14]. Substantial benefit in the treatment of unresectable hepatic tumors has been shown by combining high-dose regional chemotherapy, predominantly melphalan [15-18], with the application of tumor necrosis factor (TNF)- $\alpha$. Because of its serious systemic side effects, including vasoplegia, TNF- $\alpha$ has only been given in isolated hepatic perfusion [15] and isolated limb perfusion [19]. Recombinant human TNF- $\alpha$ has been demonstrated to exert an inhibiting effect on angiogenic tumor vessels [20] and, additionally, to induce distinct damaging effects on the tumor-supplying vasculature [21]. The latter include the increase of the endothelial permeability [22], leading to improved chemotherapy penetration to the tumor tissue [23], and a selective destruction of angiogenic endothelial cells, resulting in tumor vessel obliteration with breakdown of the nutritional tumor perfusion and excessive tumor necrosis $[24,25]$.

Apart from these direct effects of TNF- $\alpha$ on the tumor vasculature, little is known about the effects of TNF- $\alpha$ on the host vasculature. After application of TNF- $\alpha$ via the HA, the highest TNF- $\alpha$ concentration should be found in the arterial branches of the hepatic microcirculation. So far, however, it is not known to which extent autochthonous liver perfusion is affected by application of TNF- $\alpha$ in HAI. As there is no data for nonisolated liver perfusion with TNF- $\alpha$ available thus far, choosing the dosage has to be oncologically effective without being harmful to the patient. Therefore, TNF- $\alpha$ doses of both 20 and $40 \mu \mathrm{g} / \mathrm{kg}$ body weight were chosen, as such doses have been shown to be effective in isolated liver perfusion and isolated limb perfusion. In an experimental porcine model, the effects of HA infusion of these different doses of TNF- $\alpha$ on hepatic circulation and microvascular perfusion were analyzed.

\section{Material and Methods}

The experiments were approved by the local ethics committee (Landesamt für Gesundheit und Verbraucherschutz, ethical approval code: 32/04) and conformed to the United Kingdom Coordinating Committee on Cancer Research (UKCCCR) Guidelines for the Welfare of Animals in Experimental Neoplasia and the NIH Guide for Care and Use of Laboratory Animals.

\section{Animals and Anesthesia}

Eighteen pigs of the Swabian Hall strain of either sex with a mean body weight of $24.3 \pm 1.2 \mathrm{~kg}(\mathrm{p}=0.899)$ were used. Animals had free access to tap water and a standard diet (Raiffeisen, Cologne, Germany). After a 7-day adaptation period, food, but not water, was withheld for $24 \mathrm{~h}$ before the experiments. After intramuscular premedication with $10 \mathrm{mg} / \mathrm{kg}$ azaperone (Stresnil; Janssen, Neuss, Germany) and $10 \mathrm{mg} / \mathrm{kg}$ metomidate hydrochloride (Hypnodil; Janssen), general anesthesia was induced by intravenous injection of $1 \mathrm{mg} / \mathrm{kg}$ etomidate (Hypnomidate; Janssen) into an ear vein. The animals were then intubated and ventilated mechanically (Dräger Avl; Dräger, Lübeck, Germany) with a mixture of oxygen and room air $\left(\mathrm{FiO}_{2} 0.30\right.$, PEEP $5 \mathrm{~mm}$ $\mathrm{Hg}$ ). The ventilation was adjusted to maintain the $\mathrm{PaO}_{2}$ above $13.3 \mathrm{kPa}$ and the $\mathrm{PaCO}_{2}$ between 4.7 and $5.3 \mathrm{kPa}$ at baseline. Balanced anesthesia was achieved throughout the experiment by intravenous infusion of $2-4 \mathrm{mg} / \mathrm{kg} / \mathrm{h}$ thiopental sodium (Trapanal; Byk Gulden, Konstanz, Germany) through a central venous catheter inserted into the right internal jugular vein. $\mathrm{NaCl}(0.9 \%$; $154 \mathrm{mmol} / \mathrm{l}$ ) was infused intravenously at a rate of $12-15 \mathrm{ml} /$ $\mathrm{kg} / \mathrm{h}$ throughout the experiment [26]. At the end of the experiment, the animals were killed by intravenous injection of a lethal dose of thiopental sodium while the animals were fully anesthetized.

\section{Surgical Preparation and Hemodynamic Analysis}

The anesthetized animals were placed in a supine position on a warming blanket. Continuous fluid supply was performed via a central venous catheter. Mean arterial blood pressure (MAP) was continuously monitored by connection of a catheter in the left femoral artery to a pressure gauge (Statham Typ P23 ID; Gould Inc., Oxnard, Calif., USA).

After midline laparotomy, the splenic vein was cannulated to measure the portal venous pressure (PVP) and the gastroduodenal artery was cannulated to perform the HAI.

\section{Flow Measurement}

To measure hepatic blood perfusion, the hepatoduodenal ligament was dissected and precalibrated ultrasonic transit-time flow probes (Transonic Systems Inc., Ithaca, N.Y., USA) were placed around the HA and the portal vein. The flow probes were connected to an ultrasound blood flow meter (T206 Animal Research Flowmeter, Transonic Systems) [27-29]. This allowed the simultaneous assessment of HA and PV blood flow without the risk of mechanical obstruction or kinking of the blood vessels [27].

\section{Laser Doppler Fluxmetry}

For monitoring of hepatic microvascular blood flow, laser Doppler fluxmetry (LDF; PeriFlux System 5000, Perimed, Stockholm, Sweden) was used [30, 31]. Blood flow was measured by placing the laser Doppler probe on three different areas of the 
liver surface in the center of the right and the left lobe. Each measurement was recorded for at least $30 \mathrm{~s}$. Care was taken to ensure continuous and steady contact with the tissue under investigation and to prevent motion disturbances from respiration and gastrointestinal peristalsis throughout the experiment [32].

\section{Experimental Protocol}

At the end of surgical preparation, 30 min were allowed for stabilization before at least 5 baseline readings were obtained. To study the effects of TNF- $\alpha$ on the hepatic perfusion, animals were randomly allocated to three groups. In the first group, HAI was performed with normal saline infusion $(0.9 \% \mathrm{NaCl} ; \mathrm{n}=6)$. In group 2, HAI was performed with $20 \mu \mathrm{g} / \mathrm{kg}$ body weight TNF$\alpha$ (recombinant human TNF- $\alpha$; 4.9-5.5 $\times 10^{7} \mathrm{U} / \mathrm{mg}$; Boehringer Ingelheim $\mathrm{GmbH}$, Ingelheim, Germany; $\mathrm{n}=6$ ). In group 3, HAI was performed with $40 \mu \mathrm{g} / \mathrm{kg}$ body weight TNF- $\alpha(\mathrm{n}=6)$. HAI was performed over a 15 -min period with an infusion rate of $100 \mathrm{ml} / \mathrm{h}$ by means of an electronically steered syringe pump (B. Braun, Melsungen, Germany), which was filled with $25 \mathrm{ml}$ physiological saline and the body weight-adapted amount of TNF- $\alpha$. During HAI, no additional fluid was given. After HAI, systemic and hepatic hemodynamic parameters were recorded every $10 \mathrm{~min}$ for a total of $2 \mathrm{~h}$. Thereafter, $250 \mathrm{ml} \mathrm{HAES} \mathrm{(6 \% )} \mathrm{was}$ administered for resuscitation [33] during $10 \mathrm{~min}$ in all groups and hemodynamic parameters were recorded for a further 30 min.

\section{Statistics}

All values are expressed as means \pm SEM. After analysis of normal distribution and equal variance of the data, differences within each group were calculated by a one-way analysis of variance (ANOVA) followed by an appropriate post-hoc test, which included the correction of the $\alpha$-error according to Bonferroni probabilities to compensate for multiple comparisons. Differences between the three groups were analyzed by ANOVA followed by the Student-Newman-Keul test. Overall statistical significance was set at $\mathrm{p}<0.05$. Statistical analysis was performed with the use of SigmaStat (SPSS Inc., Chicago, Ill., USA).

\section{Results}

All animals survived the surgical preparation as well as the HA infusion with 20 or $40 \mu \mathrm{g} / \mathrm{kg} \mathrm{TNF}-\alpha$. During the entire observation period no complications like bleeding, cardiac failure, pulmonary dysfunction, or lung edema could be observed. Body temperature at baseline was $35.7 \pm 0.3^{\circ} \mathrm{C}(\mathrm{p}=0.681)$ and declined during the observation period to $34.3 \pm 0.4^{\circ} \mathrm{C}(\mathrm{p}=0.377)$ without any significant differences between the groups. At the beginning of the experiments, hematocrit was $24.9 \pm 0.8 \%$ $(\mathrm{p}=0.867)$ and decreased slightly to $23.7 \pm 0.9 \%(\mathrm{p}=$ 0.777 ) due to repeated blood withdrawals and surgeryassociated blood loss. However, there was no significant difference between the baseline hematocrit and the hematocrit at the end of the experiment.

HAI with TNF- $\alpha$ Induces Hepatic Hyperperfusion

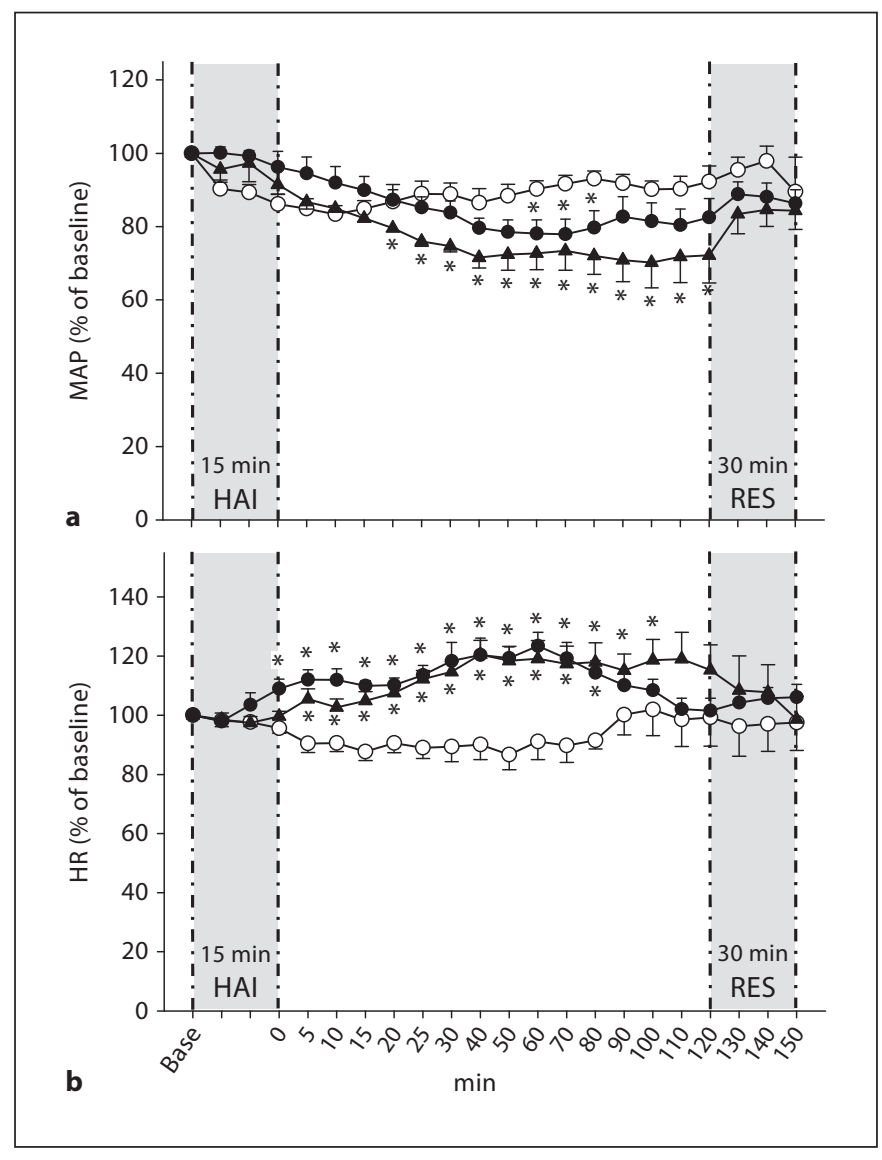

Fig. 1. MAP (a) and HR (b) in percent of baseline (base) and during HAI as well as during the 120 -min post-HAI period and during the $30 \mathrm{~min}$ after HAES resuscitation (RES). HAI was performed either with $\mathrm{NaCl}(\bigcirc)$ or $20 \mu \mathrm{g} / \mathrm{kg}$ TNF- $\alpha(\bullet)$ and $40 \mu \mathrm{g} /$ kg TNF- $\alpha(\boldsymbol{\Delta})$. Mean \pm SEM; ${ }^{*} \mathrm{p}<0.05$ vs. $\mathrm{NaCl}$ controls.

\section{Systemic Hemodynamics}

At baseline, MAP in control animals was $115 \pm 5 \mathrm{~mm}$ $\mathrm{Hg}$. During HAI and after the first $15 \mathrm{~min}$ following HAI, MAP decreased about $18 \%$, but spontaneously normalized during the subsequent 2-hour observation period (fig. 1a). MAP was not significantly affected by resuscitation with $250 \mathrm{ml}$ HAES. HAI with $20 \mu \mathrm{g} / \mathrm{kg} \mathrm{TNF}-\alpha$ (baseline $121 \pm 6 \mathrm{~mm} \mathrm{Hg}$ ) and in particular with $40 \mu \mathrm{g} /$ $\mathrm{kg}$ TNF- $\alpha$ (baseline $113 \pm 10 \mathrm{~mm} \mathrm{Hg}$ ) resulted in a 20 and $30 \%$ decrease of MAP ( $p<0.001$; fig. 1a). Resuscitation with $250 \mathrm{ml}$ HEAS effectively restored MAP in TNF$\alpha$-treated animals to values almost similar to that of controls (fig. 1a).

In control animals, heart rate (HR) at baseline was 77 $\pm 3 \mathrm{~min}^{-1}$. In line with the decrease of MAP, HR in controls slightly decreased during HAI and the following 15 


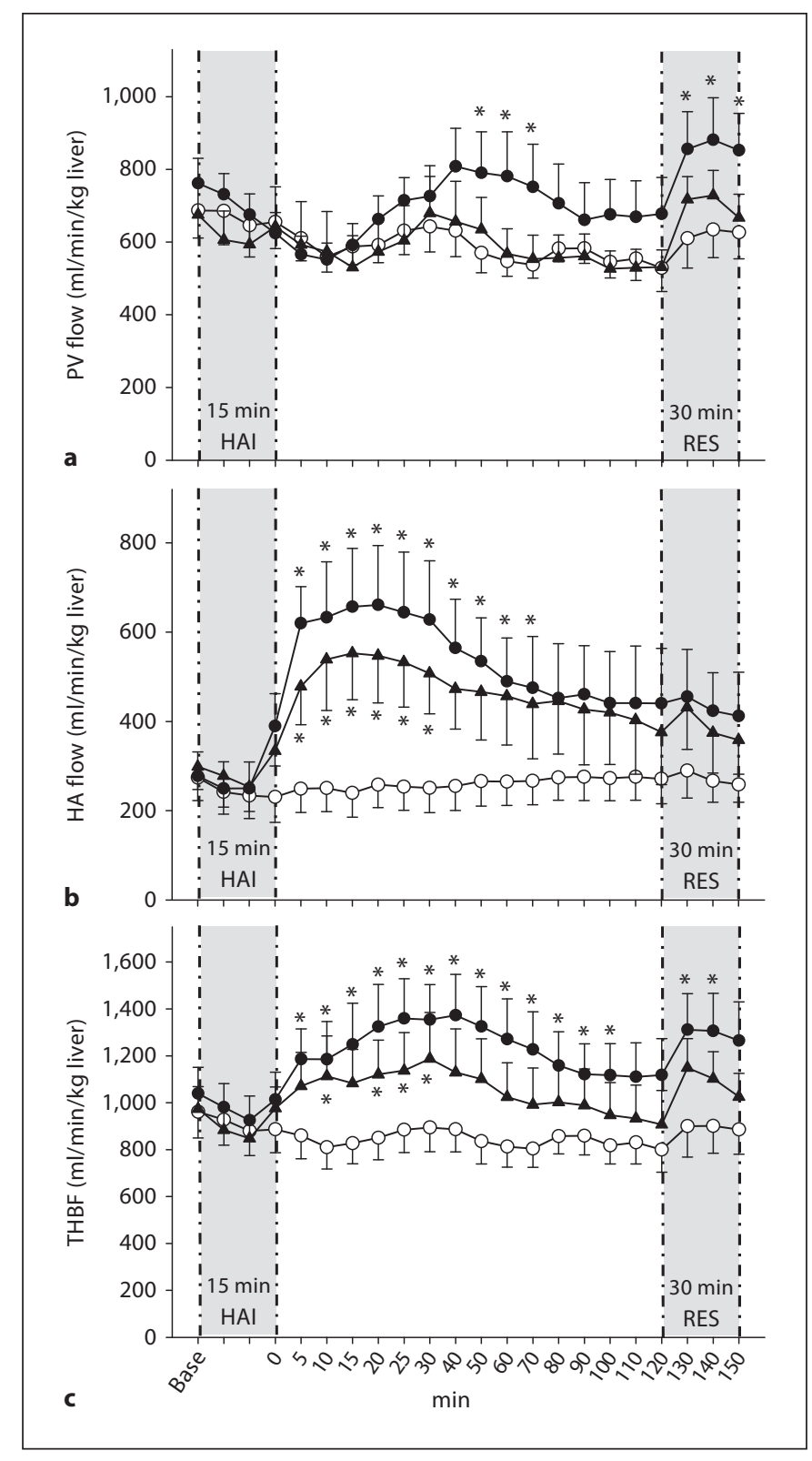

Fig. 2. PV flow (a), hepatic arterial flow (HA flow; b) and THBF (c) at baseline (base) and during HAI as well as during the 120 min post HAI period and during the 30 min after HAES resuscitation (RES). HAI was performed either with $\mathrm{NaCl}(\bigcirc)$ or $20 \mu \mathrm{g} /$ $\mathrm{kg}$ TNF- $\alpha(\bullet)$ and $40 \mu \mathrm{g} / \mathrm{kg}$ TNF- $\alpha(\mathbf{\Delta})$. Mean $\pm \mathrm{SEM}$; ${ }^{*} \mathrm{p}<0.05$ vs. $\mathrm{NaCl}$ controls.

min, but spontaneously normalized to baseline level. Resuscitation with HAES did not influence HR (fig. 1b). TNF- $\alpha$ treatment in a dose of $20 \mu \mathrm{g} / \mathrm{kg}$ caused an approximate $25 \%$ increase of HR at $1 \mathrm{~h}$ after HAI $(\mathrm{p}<0.001)$ which spontaneously normalized by $120 \mathrm{~min}$ of observa- tion. Resuscitation with HAES did not significantly affect HR in these animals (fig. 1b). In animals treated with $40 \mu \mathrm{g} / \mathrm{kg}$ TNF- $\alpha$, HR was found increased over the entire 120 -min observation period $(\mathrm{p}<0.001)$. Of interest, resuscitation with HAES immediately normalized HR to baseline levels (fig. 1b).

\section{PV and Hepatic Arterial Blood Flow}

In control animals, PV blood flow at baseline was 687 $\pm 76 \mathrm{ml} / \mathrm{min} / \mathrm{kg}$ liver weight. HAI with saline caused a decrease of PV blood flow to $563 \pm 35 \mathrm{ml} / \mathrm{min} / \mathrm{kg}$ liver weight, from $762 \pm 69$ to $552 \pm 50 \mathrm{ml} / \mathrm{min} / \mathrm{kg}$ liver weight $(20 \mu \mathrm{g} / \mathrm{kg})$, and from $675 \pm 90$ to $531 \pm 87 \mathrm{ml} /$ $\mathrm{min} / \mathrm{kg}$ liver weight $(40 \mu \mathrm{g} / \mathrm{kg})$, respectively, which persisted over the entire 120 -min observation period. Resuscitation with HAES restored PV blood flow (fig. 2a). HAI with $20 \mu \mathrm{g} / \mathrm{kg}$ TNF- $\alpha$ decreased PV blood flow by approximately $25 \%$ during HAI and the following $10 \mathrm{~min}$. This depression of PV blood flow spontaneously recovered, presenting with baseline values significantly exceeding PV blood flow values of controls $(p=0.048)$. Resuscitation with HAES caused a significant increase of PV blood flow ( $\mathrm{p}=0.046$; fig. 2a). Of interest, HAI with $40 \mu \mathrm{g} / \mathrm{kg}$ TNF- $\alpha$ caused a less pronounced decrease of PV blood flow compared to that observed after HAI with $20 \mu \mathrm{g} / \mathrm{kg}$ TNF- $\alpha$, which, however, was persistent over the entire 120-min observation period. Resuscitation with HAES restored PV blood flow (fig. 2a).

In control animals hepatic arterial blood flow was 274 $\pm 51 \mathrm{ml} / \mathrm{min} / \mathrm{kg}$ liver weight at baseline and remained unaffected during the entire course of the experiment. HAI with $20 \mu \mathrm{g} / \mathrm{kg}$ TNF- $\alpha$ caused a 2.5 -fold increase of HA blood flow from $278 \pm 54$ to $660 \pm 133 \mathrm{ml} / \mathrm{min} / \mathrm{kg}$ liver weight within the first $15 \mathrm{~min}$ after TNF- $\alpha$ application ( $p=0.023$; fig. $2 b$ ). Of interest, HA blood flow remained elevated throughout the entire observation period. In animals treated with $40 \mu \mathrm{g} / \mathrm{kg}$ TNF- $\alpha$, HA blood flow also showed an early increase after TNF- $\alpha$ application from $299 \pm 51 \mathrm{ml} / \mathrm{min} / \mathrm{kg}$ liver weight $(\mathrm{p}=0.034$; fig. 2b), although the peak value of $547 \pm 106 \mathrm{ml} / \mathrm{min} / \mathrm{kg}$ liver weight was lower compared to that measured after application of $20 \mu \mathrm{g} / \mathrm{kg}$ TNF- $\alpha$. In both groups, resuscitation did not affect HA blood flow (fig. 2b).

In control animals, total hepatic blood flow (THBF) was $961 \pm 111 \mathrm{ml} / \mathrm{min} / \mathrm{kg}$ liver weight at baseline. According to PV and HA blood flow, THBF remained unchanged during the entire course of the experiment. In animals treated with $20 \mu \mathrm{g} / \mathrm{kg}$ TNF- $\alpha$, THBF was found significantly increased (from $1,039 \pm 111$ to $1,359 \pm 149 \mathrm{ml}$ / $\mathrm{min} / \mathrm{kg}$ liver weight) after HAI ( $\mathrm{p}=0.019$; fig. $2 \mathrm{c}$ ). In ani- 


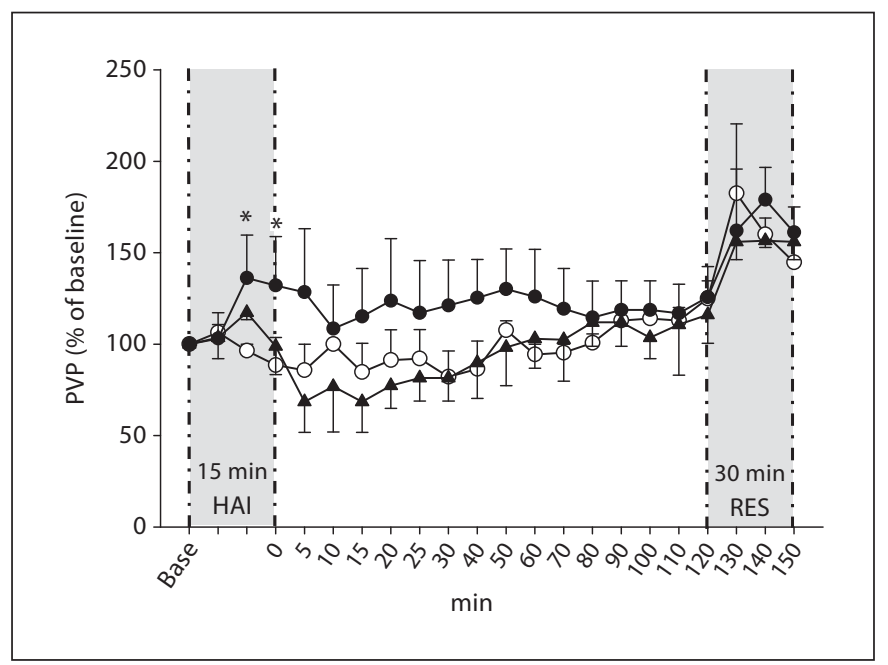

Fig. 3. PVP in percent of baseline (base) and during HAI as well as during the 120 -min post-HAI period and during the $30 \mathrm{~min}$ after HAES resuscitation (RES). HAI was performed either with $\mathrm{NaCl}(\bigcirc)$ or $20 \mu \mathrm{g} / \mathrm{kg}$ TNF- $\alpha(\bullet)$ and $40 \mu \mathrm{g} / \mathrm{kg}$ TNF- $\alpha(\boldsymbol{\Delta})$. Mean \pm SEM; ${ }^{*} \mathrm{p}<0.05$ vs. $\mathrm{NaCl}$ controls.

mals treated with $40 \mu \mathrm{g} / \mathrm{kg}$ TNF- $\alpha$, THBF was also found elevated after HAI (from $974 \pm 94$ to $1,187 \pm 196 \mathrm{ml} / \mathrm{min}$ / $\mathrm{kg}$ liver weight; $\mathrm{p}=0.041$ ), although this increase was less pronounced compared to that observed after application of $20 \mu \mathrm{g} / \mathrm{kg}$ TNF- $\alpha$. In both TNF- $\alpha$-treated groups, resuscitation caused a further increase of THBF (fig. 2c).

\section{Portal Venous Pressure}

In control animals PVP was $3.6 \pm 0.6 \mathrm{~mm} \mathrm{Hg}$ at the beginning of the experiments. Upon HAI with saline, PVP decreased slightly, but recovered over the course of the experiment. Resuscitation induced an approximate $50 \%$ increase of PVP within the first $10 \mathrm{~min}$ after HAES application (fig. 3). Treatment with $20 \mu \mathrm{g} / \mathrm{kg}$ TNF- $\alpha$ provoked a temporary increase of PVP already during HAI (from $6.3 \pm 0.3$ to $8.3 \pm 0.7 \mathrm{~mm} \mathrm{Hg}$; $=0.008$; fig. 3 ), which normalized during the subsequent observation period. In contrast, HAI with $40 \mu \mathrm{g} / \mathrm{kg}$ TNF- $\alpha$ caused a reduction of PVP after HAI by $32 \%$ (from $6.3 \pm 0.9$ to 4.0 $\pm 0.6 \mathrm{~mm} \mathrm{Hg}$ ), which recovered over the 120 -min observation time. Comparable to control animals, resuscitation induced a striking increase of PVP in both TNF- $\alpha$ treated groups (fig. 3).

\section{Hepatic Microcirculation}

In control animals, LDF revealed a constant blood flow in the hepatic microcirculation (zero time signal:

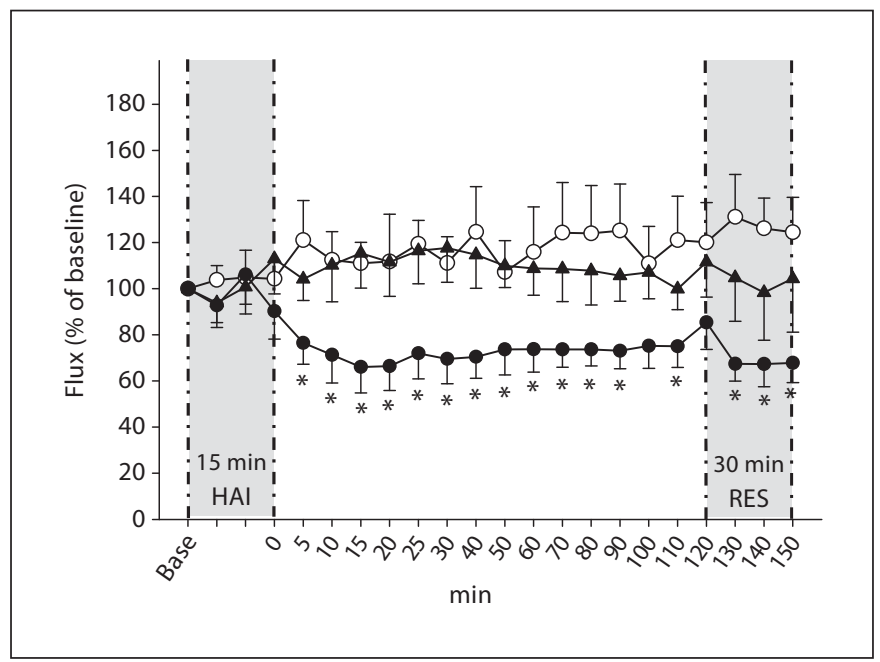

Fig. 4. Hepatic microcirculatory flux in percent of baseline (base) and during HAI as well as during the 120 -min post HAI period and during the $30 \mathrm{~min}$ after HAES resuscitation (RES). HAI was performed either with $\mathrm{NaCl}(\bigcirc)$ or $20 \mu \mathrm{g} / \mathrm{kg}$ TNF- $\alpha(\bullet)$ and 40 $\mu \mathrm{g} / \mathrm{kg}$ TNF- $\alpha(\boldsymbol{\Delta})$. Mean $\pm \mathrm{SEM} ;{ }^{*} \mathrm{p}<0.05$ vs. $\mathrm{NaCl}$ controls.

$200 \pm 9.6$ arbitrary units) during HAI as well as during the post-HAI observation period. Resuscitation showed no significant effect on microvascular blood flow as measured by LDF (fig. 4). In animals treated with $20 \mu \mathrm{g} / \mathrm{kg}$ TNF- $\alpha$ (zero time signal: $608 \pm 79$ arbitrary units) HAI caused a significant reduction of hepatic nutritive perfusion immediately after HAI. The microvascular flux remained decreased during the entire 120-min observation period, and could not be normalized by resuscitation with HAES ( $p=0.009$; fig. 4). In contrast, HAI with 40 $\mathrm{mg} / \mathrm{kg}$ TNF- $\alpha$ (zero time signal: $464 \pm 111$ arbitrary units) showed no significant effect on the blood flow in the hepatic microcirculation as measured by LDF throughout the entire post-HAI observation period (fig. 4).

\section{Discussion}

In the present study, we investigated the effects of HAI with TNF- $\alpha$ on hepatic perfusion and microcirculation. The major finding of the present study is that HAI with TNF- $\alpha$ induces a slight and temporary decrease of PV flow which was associated with an overshooting hepatic arterial blood flow. As a consequence, HAI with TNF- $\alpha$ resulted in a $20-40 \%$ increase of total hepatic blood flow, which almost normalized during the 120-min observa- 
tion period. Of interest, while high-dose $(40 \mu \mathrm{g} / \mathrm{kg}) \mathrm{TNF}$ $\alpha$ application was not associated with significant blood flow disturbances of the hepatic microcirculation, the low-dose $(20 \mu \mathrm{g} / \mathrm{kg})$ TNF- $\alpha$ application resulted in a significant alteration of the nutritive liver perfusion.

As we have previously shown, HAI with TNF- $\alpha$ at a dose of 20 or $40 \mu \mathrm{g} / \mathrm{kg}$ body weight induces a slight depression of MAP, which is compensated by a reactive increase of HR rate [26]. This cardiovascular dysfunction after TNF- $\alpha$ administration is thought to be due to the induction of endothelium-derived vasoactive mediators such as nitric oxide [34]. Of interest, $20 \mu \mathrm{g} / \mathrm{kg}$ TNF- $\alpha$ has been shown to result in a hyperdynamic circulatory state, while a dose of $40 \mu \mathrm{g} / \mathrm{kg}$ did not affect cardiac index [26].

In the present study, we found that HAI with TNF- $\alpha$ reduces PV blood flow. This is most probably the consequence of the depression of the MAP. In general, reduced $\mathrm{PV}$ blood flow to the liver is compensated by increased arterial blood flow, a mechanism that is known as the 'hepatic arterial buffer response', thereby maintaining overall hepatic perfusion at a constant level [35]. Indeed, in our model, we observed a markedly increased hepatic arterial blood flow after HAI with TNF- $\alpha$, resulting in hepatic hyperperfusion. As the hepatic arterial buffer response is adenosine-mediated [35], we could not prove that the observed increase of underlying hepatic arterial blood flow results from this mechanism. At least, it can be speculated that arterial hyperperfusion due to a TNF$\alpha$ induced release of adenosine occurs (this release, however, does not seem to be dose-dependent), resulting in consecutive dysregulation of hepatic arterial blood flow. How far the underlying mechanism of hepatic hyperperfusion is adenosine-mediated, or may be due to other vasoactive mediators, remains to be determined in future studies.

Interestingly, the hepatic hyperperfusion was not dose-dependent because animals treated with $20 \mu \mathrm{g} / \mathrm{kg}$ TNF- $\alpha$ showed a more pronounced increase of hepatic arterial blood flow compared to animals treated with 40 $\mu \mathrm{g} / \mathrm{kg}$ TNF- $\alpha$. This may be due to the higher cardiac index observed after $20 \mu \mathrm{g} / \mathrm{kg}$ TNF- $\alpha$ compared to $40 \mu \mathrm{g} /$ kg TNF- $\alpha$ application [26].

The hepatic arterial hyperperfusion did not substantially affect PVP. This is in line with findings by Lautt and Legare [36], demonstrating an autoregulation of PVP which keeps PVP stable independent of the PV blood flow.

One may assume that there was a low hematocrit throughout all experiments, influencing the measurements of PV and hepatic arterial blood flow. However, the hematocrit values obtained in the present study were within the normal range known from the literature [37, 38]. A slight hemodilution may have occurred due to infusion of the animals by balanced anesthesia, but there was neither a difference in hematocrit between the experimental groups nor within one group throughout the duration of the experiment; therefore, the findings of the flow measurements may not be explained by the hematocrit values.

In the present study, the hepatic microcirculation was assessed by LDF, which is an established method for the estimation of the blood flow of the nutritive hepatic microcirculation $[39,40]$. Interestingly, we found a reduced hepatic nutritive perfusion upon HAI only with low-dose TNF- $\alpha$. Previous studies have shown that TNF- $\alpha$ induces endothelial injury with subsequent endothelial cell swelling, microvascular blood flow cessation, and thrombotic occlusion of sinusoids, reflecting well-known hallmarks of microvascular inflammatory injury [41-43]. However, this is probably not the cause for the reduced microcirculation observed after HAI with low-dose TNF- $\alpha$ because HAI with high-dose TNF- $\alpha$ did not affect the hepatic microcirculation and previous studies investigating HAI with $20 \mu \mathrm{g} / \mathrm{kg}$ TNF- $\alpha$ could not show thrombotic vascular occlusions, as already shown by previous research of our group [26]. Instead it may be speculated that the more pronounced hepatic hyperperfusion after low-dose compared to high-dose TNF- $\alpha$ application resulted in the deterioration of the microvascular perfusion. Although it has been demonstrated that the LDF signal from the liver reflects hepatic macrohemodynamics quite well [44], it is also known that a certain spatial and temporal heterogeneity of the LDF signal on the liver surface exists [40]. Especially in pathophysiological states such as low-flow states [27] or TNF- $\alpha$ application - which has never been examined by LDF - different perfusion patterns, intrahepatic shunts, or blood flow disturbances may occur [28]. This view is supported by other experiments, demonstrating in experimental small-for-size liver transplantation models that massive hepatic hyperperfusion is associated with a deterioration of the blood flow in the hepatic microcirculation $[45,46]$. Of interest, after low-dose TNF- $\alpha$ application, the blood flow in the hepatic microcirculation did not recover during the later time course of the experiment, although the extent of hepatic hyperperfusion was found to be reduced. This observation parallels the observation of Li et al. [46], demonstrating sustained hepatic microcirculatory disturbances after portal hypertension lasting only $1 \mathrm{~h}$ in small-for-size liver transplantation. 
Resuscitation with $250 \mathrm{ml}$ HAES was effective to restore systemic hemodynamics, including normalization of both MAP and HR. This is in line with the established clinical practice using HAES to increase blood volume and to stabilize hemodynamic conditions [33]. Interestingly, resuscitation did not affect hepatic arterial perfusion, but substantially increased PV blood flow. This is most probably a result of the restored intestinal perfusion. The increased intestinal blood volume results in an increase of PVP, as observed in the present study in all groups.

TNF- $\alpha$ has a short half-life time of 14-18 $\min$ [47], and a high first-pass effect in the liver. Upon HAI, a large extent of the TNF- $\alpha$ is bound in the liver. As a consequence, systemic concentrations of TNF- $\alpha$ are low, avoiding major systemic side effects. In line with this view, our study demonstrates that the application of TNF- $\alpha$ to the HA is well tolerated without severe systemic side effects. Macrocirculatory parameters were only slightly influenced by the administration of TNF- $\alpha$. This absence of systemic cardiovascular failure might be explained by a substantial TNF- $\alpha$ binding in the liver during the first pass of HAI.

In summary, we demonstrated herein that HAI of TNF- $\alpha$ induces a decrease of PV flow which is compen- sated by an increase of hepatic arterial flow, which is not related to the dose of TNF- $\alpha$ applied. A lower dose of 20 $\mu \mathrm{g} / \mathrm{kg}$ body weight TNF- $\alpha$ leads to a higher hepatic arterial blood flow than the higher dose of $40 \mu \mathrm{g} / \mathrm{kg}$ body weight, which may be explained by TNF- $\alpha$ related blood flow disturbances that are not dose-dependent. A slight overcompensation of the portal flow decrease by hepatic arterial hyperperfusion does not affect the blood flow in the hepatic microcirculation, while a more pronounced hepatic arterial hyperperfusion may impact hepatic microvasculature. In this study, we could demonstrate for the first time that an oncological effective dosage of TNF$\alpha$ in nonisolated liver perfusion is feasible without severe systemic side effects. These findings could influence the therapy of patients with liver malignancies in order to perform hepatic perfusion without the need for vascular isolation of the liver.

\section{Acknowledgement}

We appreciate the excellent technical assistance of Elisabeth Gluding.

\section{References}

1 Segall HN: An experimental anatomical investigation of the blood and bile channels of the liver. Surg Gynecol Obstet 1923;37:152178.

-2 Lin G, Lunderquist A, Hägerstrand I, Boijsen E: Postmortem examination of the blood supply and vascular pattern of small liver metastases in man. Surgery 1984; $96: 517-$ 526.

- 3 Sullivan RD, Norcross JW, Watkins E Jr: Chemotherapy of metastatic liver cancer by prolonged hepatic-artery infusion. N Engl J Med 1964;270:321-327.

-4 Sigurdson ER, Ridge JA, Kemeny N, Daly JM: Tumor and liver drug uptake following hepatic artery and portal vein infusion. J Clin Oncol 1987;5:1836-1840.

5 Rothbarth J, Sparidans RW, Beijnen JH, Schultze-Kool LJ, Putter H, van de Velde CJ, Mulder GJ: Reduced liver uptake of arterially infused melphalan during retrograde rat liver perfusion with unaffected liver tumor uptake. J Pharmacol Exp Ther 2002;303: 736-740.

-6 Kemeny N, Daly J, Reichman B, Geller N, Botet J, Oderman P: Intrahepatic or systemic infusion of fluorodeoxyuridine in patients with liver metastases from colorectal carcinoma. A randomized trial. Ann Intern Med 1987;107:459-465.
7 Chang AE, Schneider PD, Sugarbaker PH, Simpson C, Culnane M, Steinberg SM: A prospective randomized trial of regional versus systemic continuous 5 -fluorodeoxyuridine chemotherapy in the treatment of colorectal liver metastases. Ann Surg 1987; 206:685-693.

8 Hohn DC, Stagg RJ, Friedman MA, Hannigan JF Jr, Rayner A, Ignoffo RJ, Acord P, Lewis $\mathrm{BJ}$ : A randomized trial of continuous intravenous versus hepatic intraarterial floxuridine in patients with colorectal cancer metastatic to the liver: the Northern California Oncology Group trial. J Clin Oncol 1989; 7:1646-1654.

-9 Martin JK Jr, O'Connell MJ, Wieand HS, Fitzgibbons RJ Jr, Mailliard JA, Rubin J, Nagorney DM, Tschetter LK, Krook JE: Intraarterial floxuridine vs systemic fluorouracil for hepatic metastases from colorectal cancer. A randomized trial. Arch Surg 1990;125: 1022-1027.

10 Rougier P, Laplanche A, Huguier M, Hay JM, Ollivier JM, Escat J, Salmon R, Julien M, Roullet Audy JC, Gallot D: Hepatic arterial infusion of floxuridine in patients with liver metastases from colorectal carcinoma: longterm results of a prospective randomized trial. J Clin Oncol 1992;10:1112-1118.
11 Lorenz M, Muller HH: Randomized, multicenter trial of fluorouracil plus leucovorin administered either via hepatic arterial or intravenous infusion versus fluorode-oxyuridine administered via hepatic arterial infusion in patients with nonresectable liver metastases from colorectal carcinoma. J Clin Oncol 2000;18:243-254.

12 Chan R, Kerr D: Hepatic arterial chemotherapy for colorectal cancer liver metastases: a review of advances in 2003. Curr Opin Oncol 2004;16:378-384.

13 Kemeny N, Capanu M, D’Angelica M, Jarnagin W, Haviland D, Dematteo R, Fong Y: Phase I trial of adjuvant hepatic arterial infusion (HAI) with floxuridine (FUDR) and dexamethasone plus systemic oxaliplatin, 5-fluorouracil and leucovorin in patients with resected liver metastases from colorectal cancer. Ann Oncol 2009;20:12361241.

-14 Kemeny NE, Jarnagin WR, Capanu M, Fong Y, Gewirtz AN, Dematteo RP, D'Angelica MI: Randomized phase II trial of adjuvant hepatic arterial infusion and systemic chemotherapy with or without bevacizumab in patients with resected hepatic metastases from colorectal cancer. J Clin Oncol 2011;29: 884-889. 
15 Grover A, Alexander HR Jr: The past decade of experience with isolated hepatic perfusion. Oncologist 2004;9:653-664.

-16 DeVries MR, Borel Rinkes IHM, Buurman WA, et al: Soluble TNF- $\alpha$ receptor induction by isolated hepatic perfusion with TNF- $\alpha$ and melphalan. Eur Surg Res 1995;27:108a.

17 Hafström L, Naredi P: Isolated hepatic perfusion with extracorporeal oxygenation using hyperthermia TNF $\alpha$ and melphalan: Swedish experience. Recent Results Cancer Res 1998;147:120-126.

18 Alexander Jr HR, Bartlett DL, Libutti SK, et al: Isolated hepatic perfusion with tumor necrosis factor and melphalan for unresectable cancers confined to the liver. J Clin Oncol 1998; 16:1479-1489.

19 Eggermont AM, Schraffordt Koops H, Klausner JM, Kroon BB, Schlag PM, Liénard D, van Geel AN, Hoekstra HJ, Meller I, Nieweg OE, Kettelhack C, Ben-Ari G, Pector JC, Lejeune FJ: Isolated limb perfusion with tumor necrosis factor and melphalan for limb salvage in 186 patients with locally advanced soft tissue extremity sarcomas. The cumulative multicenter European experience. Ann Surg 1996;224:756-765.

20 van Etten B, de Vries MR, van IJken MG, Lans TE, Guetens G, Ambagtsheer G, van Tiel ST, de Boeck G, de Bruijn EA, Eggermont AM, ten Hagen TL: Degree of tumour vascularity correlates with drug accumulation and tumour response upon TNF-alphabased isolated hepatic perfusion. Br J Cancer 2003;88:314-319.

-21 Lejeune FJ, Liénard D, Matter M, Rüegg C: Efficiency of recombinant human TNF in human cancer therapy. Cancer Immun 2006; 6:6.

22 Worrall NK, Chang K, LeJeune WS, Misko TP, Sullivan PM, Ferguson TB Jr, Williamson JR: TNF-alpha causes reversible in vivo systemic vascular barrier dysfunction via NO-dependent and -independent mechanisms. Am J Physiol 1997;273:H2565H2574.

23 Eggermont AM, ten Hagen TL: Isolated limb perfusion for extremity soft-tissue sarcomas, in-transit metastases, and other unresectable tumors: credits, debits, and future perspectives. Curr Oncol Rep 2001;3:359-367.

-24 Renard N, Lienard D, Lespagnard L, Eggermont A, Heimann R, Lejeune F: Early endothelium activation and polymorphonuclear cell invasion precede specific necrosis of human melanoma and sarcoma treated by intravascular high-dose tumour necrosis factor alpha (rTNF alpha). Int J Cancer 1994;57: 656-663.
25 ten Hagen TL, Seynhaeve AL, Eggermont AM: Tumor necrosis factor-mediated interactions between inflammatory response and tumor vascular bed. Immunol Rev 2008;222: 299-315.

-26 Schäfer T, Sperling J, Kollmar O, Richter S, Schilling MK, Menger MD, Lindemann W: Early effect of hepatic artery TNF-alpha infusion on systemic hemodynamics and inflammation: a dose-response study in pigs. Int J Colorectal Dis 2010;25:523-532.

27 Richter S, Mücke I, Menger MD, Vollmar B: Impact of intrinsic blood flow regulation in cirrhosis: maintenance of hepatic arterial buffer response. Am J Physiol Gastrointest Liver Physiol 2000;279:G454-G462.

28 Richter S, Vollmar B, Mücke I, Post S, Menger MD: Hepatic arteriolo-portal venular shunting guarantees maintenance of nutritional microvascular supply in hepatic arterial buffer response of rat livers. J Physiol 2001;531: 193-201.

29 Tenhunen JJ, Uusaro A, Kärjä V, Oksala N, Jakob SM, Ruokonen E: Apparent heterogeneity of regional blood flow and metabolic changes within splanchnic tissues during experimental endotoxin shock. Anesth Analg 2003;97:555-563.

30 Kollmar O, Corsten M, Scheuer C, Vollmar B, Schilling MK, Menger MD: Portal branch ligation induces a hepatic arterial buffer response, microvascular remodeling, normoxygenation, and cell proliferation in portal blood-deprived liver tissue. Am J Physiol Gastrointest Liver Physiol 2007;292:G1534G1542.

-31 Eipel C, Glanemann M, Nuessler AK, Menger MD, Neuhaus P, Vollmar B: Ischemic preconditioning impairs liver regeneration in extended reduced-size livers. Ann Surg 2005;241:477-484.

32 Krejci V, Hiltebrand LB, Jakob SM, Takala J, Sigurdsson GH: Vasopressin in septic shock: effects on pancreatic, renal, and hepatic blood flow. Crit Care 2007;11:R129.

33 Palumbo D, Servillo G, D’Amato L, Volpe ML, Capogrosso G, De Robertis E, Piazza O, Tufano R: The effects of hydroxyethyl starch solution in critically ill patients. Minerva Anestesiol 2006;72:655-664

-34 Mitaka C, Hirata Y, Ichikawa K, Yokoyama K, Emori T, Kanno K, Amaha K: Effects of TNF-alpha on hemodynamic changes and circulating endothelium-derived vasoactive factors in dogs. Am J Physiol 1994; 267:H1530-H1536.

35 Lautt WW: Relationship between hepatic blood flow and overall metabolism: the hepatic arterial buffer response. Fed Proc 1983; 42:1662-1666.
36 Lautt WW, Legare DJ: Passive autoregulation of portal venous pressure: distensible hepatic resistance. Am J Physiol 1992; 263:G702-G708

- 37 Faustini M, Munari E, Colombani C, Russo V, Maffeo G, Vigo D: Haematology and plasma biochemistry of Stamboek pre-pubertal gilts in Italy: reference values. J Vet Med A Physiol Pathol Clin Med 2000;47:525-532.

- 38 Egeli AK, Framstad T, Morberg H: Clinical biochemistry, haematology and body weight in piglets. Acta Vet Scand 1998;39:381-393.

39 Almond NE, Wheatley AM: Measurement of hepatic perfusion in rats by laser Doppler flowmetry. Am J Physiol 1992;262:G203G209.

40 Richter S, Sperling J, Kollmar O, Menger MD, Schilling MK, Chirurgische Arbeitsgemeinschaft OP-Technik und OP-Strukturen of the Deutsche Gesellschaft für Chirurgie: Laser Doppler flowmetry of hepatic microcirculation during Pringle's maneuver: determination of spatial and temporal liver tissue perfusion heterogeneity. Eur Surg Res 2010;44:152-158.

-41 Katagiri H, Ito Y, Ito S, Murata T, Yukihiko S, Narumiya S, Watanabe M, Majima M: TNF-alpha induces thromboxane receptor signaling-dependent microcirculatory dysfunction in mouse liver. Shock 2008;30:463467.

42 Vollmar B, Glasz J, Leiderer R, Post S, Menger $\mathrm{MD}$ : Hepatic microcirculatory perfusion failure is a determinant of liver dysfunction in warm ischemia-reperfusion. Am J Pathol 1994;145:1421-1431.

43 McCuskey RS, Urbaschek R, McCuskey PA, Urbaschek B: In vivo microscopic studies of the responses of the liver to endotoxin. Klin Wochenschr 1982;60:749-751.

44 Wheatley AM, Hickman R: The influence of flow and hematocrit on the laser Doppler flux signal from the surface of the perfused pig liver. Microcirculation 1995:19-25.

-45 Tian Y, Jochum W, Georgiev P, Moritz W, Graf R, Clavien PA: Kupffer cell-dependent TNF-alpha signaling mediates injury in the arterialized small-for-size liver transplantation in the mouse. Proc Natl Acad Sci USA 2006;103:4598-4603.

46 Li J, Liang L, Ma T, Yu X, Chen W, Xu G, Liang T: Sinusoidal microcirculatory changes after small-for-size liver transplantation in rats. Transpl Int 2010;23:924-933.

-47 Blick M, Sherwin SA, Rosenblum M, Gutterman J: Phase I study of recombinant tumor necrosis factor in cancer patients. Cancer Res 1987;47:2986-2989. 